\title{
Pharmaceutical hydrates under ambient conditions from high-pressure seeds: a case study of GABA monohydrate $\dagger+$
}

Cite this: Chem. Commun., 2014 50, 1817

Received 5th November 2013, Accepted 26th November 2013

DOI: $10.1039 / c 3 c c 48466 a$

www.rsc.org/chemcomm

\author{
Francesca P. A. Fabbiani, ${ }^{\star a}{ }^{a}$ Gernot Buth, ${ }^{b}$ Demetrius C. Levendis ${ }^{c}$ and \\ Aurora J. Cruz-Cabeza*d
}

The monohydrate form of the neurotransmitter $\gamma$-amino butyric acid (GABA) has been crystallised in the $0.4-0.8 \mathrm{GPa}$ pressure range, recovered to ambient pressure and then used as a seed. Theoretical calculations indicate that this hydrate is only thermodynamically favoured over the two anhydrous forms at high pressures.

$\gamma$-Amino butyric acid (GABA) is a non-standard gamma-amino acid and the main inhibitory neurotransmitter in the central nervous system. ${ }^{1}$ GABAergic drugs have sedative and anticonvulsive effects; they are employed for the treatment of neurological disorders such as epilepsy, anxiety and Parkinson's disease. $^{2-4}$

GABA exists as a neutral molecule exhibiting extensive conformational flexibility in the gas phase ${ }^{5}$ and can exist as a zwitterion (Fig. 1) or a cation in solution and in the solid state. Two anhydrous polymorphs containing the zwitterionic form have been reported for GABA: a stable monoclinic ${ }^{6}$ and a metastable tetragonal polymorph, ${ }^{7,8}$ both of which have been crystallised from aqueous solutions. Whilst a hydrate structure of GABA has never been observed, GABA zwitterions have been suggested to form stable clusters with water (GABA. $2 \mathrm{H}_{2} \mathrm{O}$ and GABA $5 \mathrm{H}_{2} \mathrm{O}$ ) in solution. ${ }^{9}$

\footnotetext{
${ }^{a}$ GZG, Abteilung Kristallographie, Georg-August-Universität Göttingen, Göttingen, 37077, Germany. E-mail: ffabbia@gwdg.de; Fax: +49 551 399521; Tel: +49 551393935

${ }^{b}$ Karlsruhe Institute of Technology, ANKA Synchrotron Radiation Facility, Hermann-von-Helmholtz-Platz 1, D-76344 Eggenstein-Leopoldshafen, Germany ${ }^{c}$ Molecular Sciences Institute, School of Chemistry, University of the Witwatersrand, PO WITS, 2050, Johannesburg, South Africa

${ }^{d}$ Van't Hoff Institute for Molecular Sciences, University of Amsterdam,

Science Park 904, 1098 XH Amsterdam, The Netherlands.

E-mail: aurorajosecruz@gmail.com; Tel: +31205258264

$\dagger$ Celebrating 300 years of Chemistry at Edinburgh.

\# Electronic supplementary information (ESI) available: Full crystallographic details and CIF files for the high-pressure and low-temperature structures, crystal packing description and figures, comparison of torsion angles in GABA structures deposited in the CSD, details of PIXEL calculations, and details of the computational study. CCDC 969073 and 969074 . For ESI and crystallographic data in CIF or other electronic format see DOI: 10.1039/c3cc48466a
}

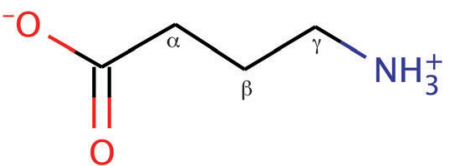

Fig. 1 Chemical diagram of the GABA zwitterion with carbon backbone naming.

Intrigued by the fact that GABA forms stable clusters with water in aqueous solutions and yet by the absence of GABA hydrates in the solid state, we set out to investigate which solid forms would result from in situ high-pressure crystallisation experiments of aqueous GABA solutions. Previous studies of small organic compounds indicate that under these conditions water tends to be included into their crystal structures. This has been shown for several small organic molecules ${ }^{10-12}$ including the pharmaceuticals paracetamol, ${ }^{13}$ piracetam, ${ }^{14}$ ciprofloxacin, ${ }^{15}$ and the GABA analogue gabapentin. ${ }^{16}$

A GABA monohydrate was reproducibly obtained by in situ high-pressure crystallisation and crystal growth in a diamondanvil cell (DAC) of the Ahsbahs type ${ }^{17}$ (Fig. 2) from a variety of aqueous solutions in the $0.4-0.8 \mathrm{GPa}$ pressure range. $\S$ The high-pressure structure was elucidated using single-crystal X-ray diffraction (SXRD) at the ANKA synchrotron.§

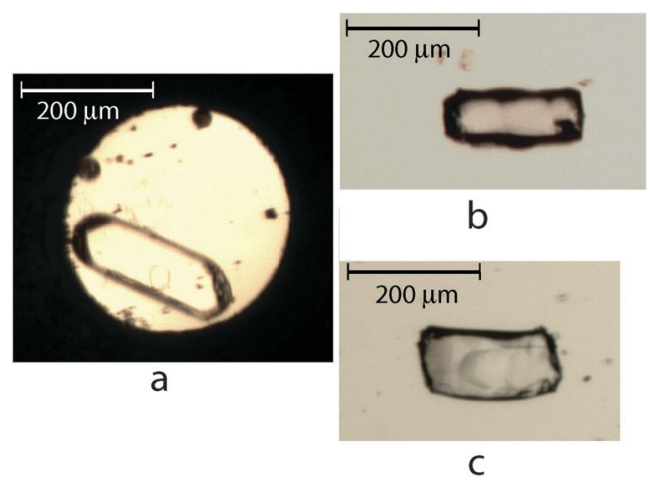

Fig. 2 Optical images of GABA monohydrate (a) at $0.44 \mathrm{GPa}$ in the DAC and (b and c) recovered to ambient temperature and rotated on its side by $90^{\circ}$. 
Recovery of the GABA monohydrate to ambient pressure proceeded in a straightforward manner and under ambienttemperature conditions (Fig. 2); the DAC was rapidly opened to prevent extensive dissolution and the crystal was immersed in mounting oil. Subsequent to recovery, SXRD data were collected at $150 \mathrm{~K}$ on our home diffractometer, confirming that no phase transition had taken place.§ High-pressure crystallisation of GABA monohydrate was repeated several times, always yielding the monohydrate and all crystals were easily recovered. Recovered crystals were then used to seed saturated aqueous solutions of GABA under ambient conditions, as confirmed using SXRD. Although no extensive crystallisation screening was conducted, we were only able to obtain the monohydrate form with the help of hydrate seeds obtained from the high-pressure crystallisations. In the absence of these seeds, all our crystallisations at ambient conditions yielded anhydrous monoclinic GABA.

A representation of the crystal structure of the GABA monohydrate is given in Fig. 3. GABA displays a folded conformation most similar to the one observed in the tetragonal polymorph (Table S3, ESI $¥$ ). Using graph-set notation, ${ }^{18}$ the main building block of the crystal structure can be described as being composed of centrosymmetric $R^{2}{ }_{2}(14)$-GABA dimers which are linked by antiparallel $\mathrm{H}$-bonded and double-stranded $C(7)$ chains running along the $b$-axis (Fig. 3 and Fig. S1, ESI ). Each strand is strengthened by accepting two H-bonds from a water molecule, which in turn links double strands related by glide symmetry. The resulting 2-D H-bonded layered structure propagates along the $c$-axis (Fig. 3 ).

PIXEL calculations ${ }^{19}$ indicate that the strongest dimer interaction in the crystal structure is associated with the GABA centrosymmetric $\mathrm{H}$-bonded dimer $\left(-389.3 \mathrm{~kJ} \mathrm{~mol}^{-1}\right)$. Whilst all interaction energies between molecular pairs linked by $\mathrm{H}$-bonding are strong and stabilising, four other non-H-bonded molecular pairs rank amongst the six energetically most significant interactions because of their favourable dipolar arrangements $(-114.7$ to $\left.-72.6 \mathrm{~kJ} \mathrm{~mol}^{-1}\right)$. These interactions are characterised by a significant Coloumbic energy contribution to the total interaction energy and a very small repulsive term (Table S4 and Fig. S3, ESI $\$$ ).

Periodic DFT calculations (PBE) ${ }^{20}$ with the Grimme van der Waals corrections $^{21}$ were performed in order to calculate the enthalpy

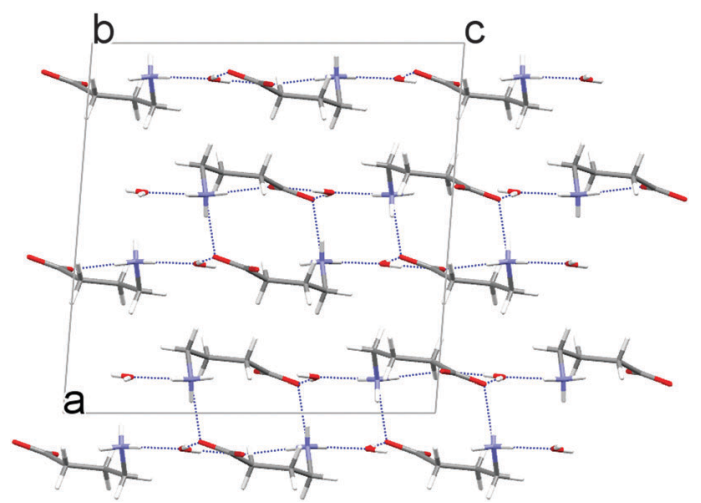

Fig. 3 2-D layered structure of GABA monohydrate viewed along the $b$ axis. $\mathrm{H}$-bonds are depicted as dotted lines.

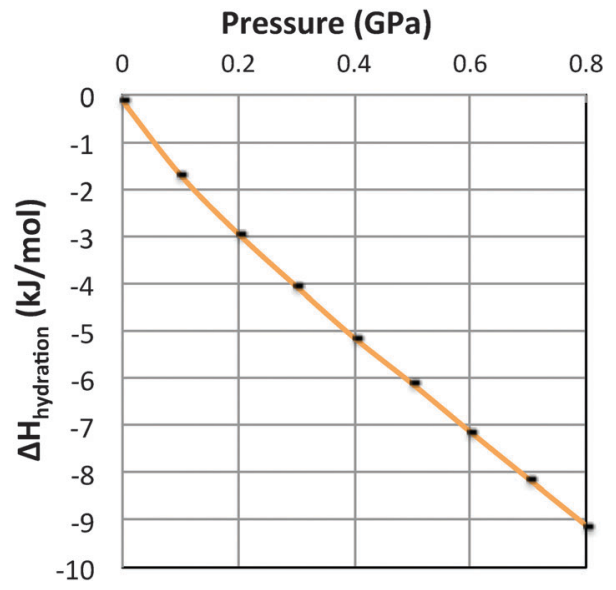

Fig. 4 Calculated hydration enthalpy of GABA as a function of pressure.

of hydration of GABA, $\Delta H_{\text {hyd }}$, as a function of pressure (Fig. 4). $\$$ At $0 \mathrm{~K}, \Delta H_{\text {hyd }}$ is defined as the difference between the enthalpy of the GABA hydrate minus the sum of the enthalpies of the most stable GABA and ice polymorphs at a given pressure. A negative $\Delta H_{\text {hyd }}$ indicates that the hydrate structure is more stable than the anhydrous form plus ice under a given set of conditions. Whilst recent ambient-pressure calculations have shown that cocrystal, solvate and hydrate formation are indeed driven by thermodynamics, ${ }^{22,23}$ to the best of our knowledge this is the first time that such calculations have been performed under a pressure range.

The change of the enthalpy of hydration with pressure is depicted in Fig. 4. At ambient pressures, close to $0 \mathrm{GPa}$, there is no driving force for hydrate formation $\left(\Delta H_{\mathrm{hyd}}=\sim 0 \mathrm{~kJ} \mathrm{~mol}{ }^{-1}\right)$. The enthalpy of the hydrate is equal to that of ice XI and the stable monoclinic GABA polymorph at $0 \mathrm{~K}$. As the pressure is increased, however, the hydration enthalpy becomes increasingly more negative, up to $-9 \mathrm{~kJ} \mathrm{~mol}^{-1}$ at $0.8 \mathrm{GPa}$. Average cocrystallisation energies lie around $-11 \mathrm{~kJ} \mathrm{~mol}^{-1}$ according to a recent study using a similar computational model. ${ }^{24}$ Our theoretical calculations nicely corroborate the experimental observations: GABA monohydrate is obtained at pressures between 0.4 and $0.8 \mathrm{GPa}$, for which the $\Delta H_{\text {hyd }}$ lies in the range from -5 up to $-9 \mathrm{~kJ} \mathrm{~mol}^{-1}$, and the monohydrate can be recovered to ambient pressures because it is energetically close to monoclinic GABA plus ice XI at those conditions $\left(\Delta H_{\text {hyd }}=\sim 0 \mathrm{~kJ} \mathrm{~mol}^{-1}\right)$. Although there is no driving force for hydrate formation at ambient conditions, if seeds of the hydrate are present in solution, growth of the hydrate occurs because the hydrate is energetically close to anhydrous GABA plus ice.

But, what is the reason for the GABA hydrate becoming more stable than the anhydrous form plus ice at higher pressures? As the pressure is increased, the enthalpies of all the involved forms become less stabilising because molecules are forced closer together and repulsions become more important (Fig. S6, ESI ). We noticed that compressing water within ice costs relatively more enthalpy than compressing water within the GABA monohydrate structure. Compression of a water molecule in ice from 0 to $0.8 \mathrm{GPa}$ occurs at a structural cost of shortening 
$4 \mathrm{H}$-bonds by $0.035 \AA$ A each and an enthalpic cost of $14 \mathrm{~kJ} \mathrm{~mol}^{-1}$. In contrast, compression of water within the GABA hydrate from 0 to $0.8 \mathrm{GPa}$ occurs at a structural cost of shortening $3 \mathrm{H}$-bonds by an average of $0.019 \AA$ each and an estimated enthalpic cost of $5 \mathrm{~kJ} \mathrm{~mol}^{-1}$. Hence, this indicates that because of the poorer compressibility of water within ice, ${ }^{25}$ hydration of GABA becomes thermodynamically favoured at higher pressures. This is likely to be the case for many other pharmaceuticals; in fact, high-pressure crystallisations are known to produce hydrates otherwise unseen under ambient conditions. ${ }^{10-16}$ Whether those hydrates can be recovered to ambient pressures and be used as seeds may be indeed anticipated using the calculations presented herein.

The phenomenon of hydrate formation has long been the subject of intensive research from both the academic and industrial communities. Approximately one third of organic molecules in the Cambridge Structural Database, ${ }^{26}$ and a similar percentage of pharmaceuticals, ${ }^{27}$ crystallise as hydrates. Hydrates actually "form an integral part of many pharmaceutical dosage forms". ${ }^{27,28}$ Whether an opportunity or a nuisance, the study of hydrate formation in the pharmaceutical industry is a necessity. In our study we have illustrated the benefits of performing crystallisation experiments under high-pressure conditions followed by the recovery of forms to ambient conditions for their use as seeds. Following that procedure, we were able to consistently produce a hydrate, otherwise elusive, at ambient conditions. Whether original seeds come from other isomorphic materials ${ }^{29}$ or from crystallisations at high-pressure conditions as shown herein, the seeding techniques can promote the realisation of otherwise unobservable forms under ambient conditions. Whilst a particular form may not find industrial applications, our study demonstrates how knowledge of the structural landscape of a compound can be extended, potentially providing useful information for devising improved manufacturing strategies and for patent protection.

We thank the German Science Foundation (DFG, Emmy Noether Grant to FPAF, FA 946/1-1) and the Netherlands Organisation for Scientific Research (VENI grant to AJCC) for financial support. We would also like to thank Dr Heidrun Sowa (Göttingen) for assistance with the synchrotron measurement, Prof. Simon Parsons (Edinburgh) for a copy of the SHADE program and Prof. Angelo Gavezzotti (Milan) for useful discussions about the CLP program.

\section{Notes and references}

$\S$ High-pressure crystallisation experiments: aqueous solutions (6-12 M) and $2: 1 \mathrm{MeOH}: \mathrm{H}_{2} \mathrm{O}$ solutions $(4 \mathrm{M})$ were loaded in beryllium-free DACs of the Ahsbahs type ${ }^{17}$ ( $45^{\circ}$ half-cell opening angle) equipped with $600 \mu \mathrm{m}$ culet diamonds and an inconel gasket with a starting diameter hole of ca. $300 \mu \mathrm{m}$. Upon increasing the pressure, precipitation of polycrystalline material was observed and a single crystal was grown by cycling the temperature inside the DAC. Crystal data for GABA monohydrate at $0.44 \mathrm{GPa}, \mathrm{CCDC}$ deposition number 969073: $\mathrm{C}_{4} \mathrm{H}_{9} \mathrm{NO}_{2} \cdot \mathrm{H}_{2} \mathrm{O}, M=121.14$, $a=14.276(6) \AA, b=5.6339(3) \AA, c=14.3645(10) \AA, \alpha=90^{\circ}, \beta=94.598(13)^{\circ}$, $\gamma=90^{\circ}, V=1151.6(5) \AA^{3}, T=296(2) \mathrm{K}$, space group $C 2 / c, Z=8$, calculated density $=1.397 \mathrm{~g} \mathrm{~cm}^{-3}, 3751$ reflections measured, 463 independent reflections $\left(R_{\text {int }}=0.051\right)$. The final $R_{1}$ value was $0.04(I>2 \sigma(I))$. The final $\mathrm{w} R\left(F^{2}\right)$ value was 0.11 (all data). Crystal data for GABA monohydrate at $150 \mathrm{~K}$, CCDC deposition number 969074: $\mathrm{C}_{4} \mathrm{H}_{9} \mathrm{NO}_{2} \cdot \mathrm{H}_{2} \mathrm{O}, M=121.14$, $a=14.3799(9) \AA, b=5.6552(4) \AA, c=14.4202(9) \AA, \alpha=90^{\circ}, \beta=94.499(3)^{\circ}$, $\gamma=90^{\circ}, V=1169.05(13) \AA^{3}, T=150(2) \mathrm{K}$, space group $C 2 / c, Z=8$, calculated density $=1.377 \mathrm{~g} \mathrm{~cm}^{-3}, 8128$ reflections measured, 1669 independent reflections $\left(R_{\text {int }}=0.0256\right)$. The final $R_{1}$ value was 0.038 $(I>2 \sigma(I))$. The final $\mathrm{w} R\left(F^{2}\right)$ value was 0.10 (all data).

1 Y. Ben-Ari, J.-L. Gaiarsa, R. Tyzio and R. Khazipov, Physiol. Rev., 2007, 87(4), 1215.

2 C. G. Wong, T. Bottiglieri and O. C. Snead, Ann. Neurol., 2003, 54, S3.

3 G. J. Sills, Curr. Opin. Pharmacol., 2006, 6(1), 108.

4 W. Froestl, Future Med. Chem., 2011, 3(2), 163.

5 S. Blanco, J. C. Lópen, S. Mata and J. L. Alonso, Angew. Chem., Int. Ed., 2010, 49, 9187.

6 E. G. Steward, R. B. Player and D. Warner, Acta Crystallogr., Sect. B, 1973, 29, 2038; H.-P. Weber, B. M. Craven and R. K. McMullan, Acta Crystallogr., Sect. B, 1983, 39, 360; B. M. Craven and H.-P. Weber, Acta Crystallogr., Sect. B, 1983, 39, 743; K.-I. Tomita, H. Higashi and T. Fujiwara, Bull. Chem. Soc. Jpn., 1973, 46, 2199.

7 A. J. Dobson and R. E. Gerkin, Acta Crystallogr., Sect. C, 1996, 52, 3075.

8 J. Vamecq, Y. Feutelais, P. Maurois, M. Sghaier, E. Dichi, M. GermanFattal, C. Herrenknecht, P. Gressens, R. Cecchelli, L. Dehouck, J. P. Stables, N. Pages, B. Legendre and P. Bac, Med. Chem. Res., 2009, 18(4), 255.

9 D. L. Crittenden, M. Chebib and M. J. R. Jordan, J. Phys. Chem. A, 2004, 108, 203.

10 F. P. A. Fabbiani, D. R. Allan, W. G. Marshall, S. Parsons, C. R. Pulham and R. I. Smith, J. Cryst. Growth, 2004, 275(1-2), 185.

11 H. Tomkowiak, A. Olejniczak and A. Katrusiak, Cryst. Growth Des., 2013, 13(1), 121.

12 A. Olejniczak and A. Katrusiak, Cryst. Growth Des., 2011, 11(6), 2250.

13 F. P. A. Fabbiani, D. R. Allan, W. I. F. David, S. A. Moggach and C. R. Pulham, CrystEngComm, 2004, 6(82), 504; I. D. H. Oswald, I. Chataigner, S. Elphick, F. P. A. Fabbiani, A. R. Lennie, J. Maddaluno, W. G. Marshall, C. R. Pulham, T. J. Prior and R. I. Smith, CrystEngComm, 2009, 11, 359.

14 F. P. A. Fabbiani, D. R. Allan, W. I. F. David, A. J. Davidson, A. R. Lennie, S. Parsons, C. R. Pulham and J. E. Warren, Cryst. Growth Des., 2007, 7, 1115.

15 F. P. A. Fabbiani, B. Dittrich, A. J. Florence, T. Gelbrich, M. B. Hursthouse, W. F. Kuhs, N. Shankland and H. Sowa, CrystEngComm, 2009, 11, 1396.

16 F. P. A. Fabbiani, D. C. Levendis, G. Buth, W. F. Kuhs, N. Shankland and H. Sowa, CrystEngComm, 2010, 12, 2354.

17 H. Ahsbahs, Z. Kristallogr., 2004, 219, 305; H. Ahsbahs, Z. Kristallogr. Suppl., 1995, 9, 42.

18 M. C. Etter, Acc. Chem. Res., 1990, 23, 120; M. C. Etter, J. C. MacDonald and J. Bernstein, Acta Crystallogr., Sect. B, 1990, 46, 256.

19 A. Gavezzotti, New J. Chem., 2011, 35, 1360; A. Gavezzotti, J. Phys. Chem., 2003, B107, 2344; A. Gavezzotti, Mol. Phys., 2008, 106, 1473.

20 J. P. Perdew, K. Burke and M. Ernzerhof, Phys. Rev. Lett., 1996, 77, 3865.

21 S. Grimme, J. Comput. Chem., 2006, 27, 1787.

22 A. T. Hulme and S. L. Price, J. Chem. Theor. Comput., 2007, 3, 1597; D. E. Braun, P. G. Karamertzanis and S. L. Price, Chem. Commun., $2011,47,5443$.

23 A. J. Cruz-Cabeza, G. M. Day, W. D. S. Motherwell and W. Jones, J. Am. Chem. Soc., 2006, 128, 14466; A. J. Cruz-Cabeza, G. M. Day and W. Jones, Chem.-Eur. J., 2008, 14, 8830; A. J. Cruz-Cabeza, S. Karki, L. Fábián, T. Friščić, G. M. Day and W. Jones, Chem. Commun., 2010, 46, 2224.

24 S. Chan, J. Kendrick, M. A. Neumann and F. Leusen, CrystEngComm, 2013, 15, 3799.

25 C. Q. Sun, X. Zhang and W. Zheng, Chem. Sci., 2012, 3, 1455.

26 L. Infantes, L. Fábián and W. D. Motherwell, CrystEngComm, 2007, $9,65$.

27 U. Griesser, in Polymorphism in the Pharmaceutical Industry, ed. R. Hilfiker, Wiley VCH Verlag GmbH \& Co. KGaA, Weinheim, 2006, p. 220.

28 R. K. Khankari and D. J. W. Grant, Thermochim. Acta, 1995, 248, 61.

29 D.-K. Bučar, G. M. Day, I. Halasz, G. G. Z. Zhang, J. R. G. Sander, D. G. Reid, L. R. MacGillivray, M. J. Duera and W. Jones, Chem. Sci., 2013, 4, 4417. 